\title{
A Streptomyces venezuelae Cell-Free Toolkit for Synthetic Biology
}

\author{
Simon J. Moore, * Hung-En Lai, Soo-Mei Chee, Ming Toh, Seth Coode, Kameshwari Chengan, \\ Patrick Capel, Christophe Corre, Emmanuel LC de los Santos, and Paul S. Freemont*
}

Cite This: ACS Synth. Biol. 2021, 10, 402-411

Read Online

\section{ACCESS I \\ 亗 Metrics \& More | 回 Article Recommendations \\ Supporting Information}

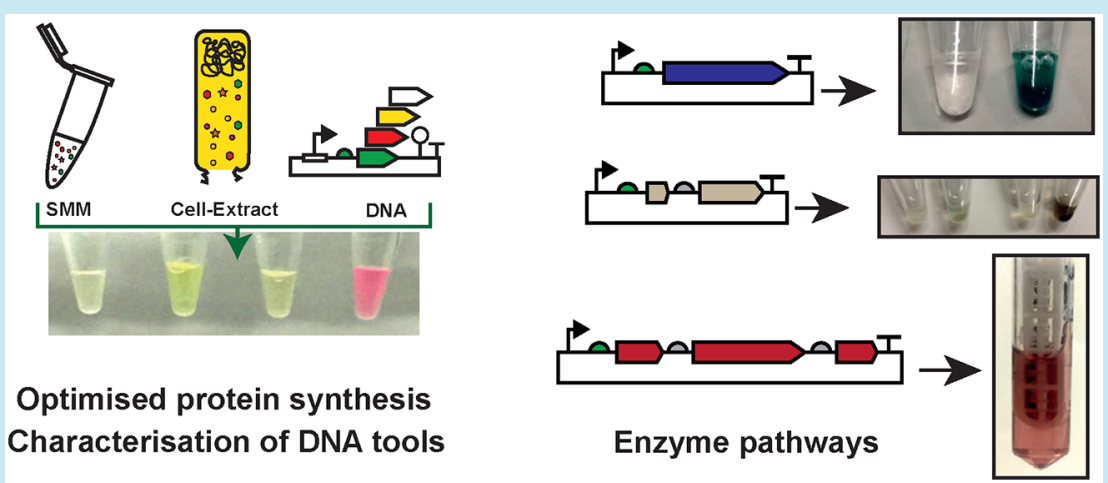

ABSTRACT: Prokaryotic cell-free coupled transcription-translation (TX-TL) systems are emerging as a powerful tool to examine natural product biosynthetic pathways in a test tube. The key advantages of this approach are the reduced experimental time scales and controlled reaction conditions. To realize this potential, it is essential to develop specialized cell-free systems in organisms enriched for biosynthetic gene clusters. This requires strong protein production and well-characterized synthetic biology tools. The Streptomyces genus is a major source of natural products. To study enzymes and pathways from Streptomyces, we originally developed a homologous Streptomyces cell-free system to provide a native protein folding environment, a high G+C (\%) tRNA pool, and an active background metabolism. However, our initial yields were low $(36 \mu \mathrm{g} / \mathrm{mL})$ and showed a high level of batch-to-batch variation. Here, we present an updated high-yield and robust Streptomyces TX-TL protocol, reaching up to yields of $266 \mu \mathrm{g} / \mathrm{mL}$ of expressed recombinant protein. To complement this, we rapidly characterize a range of DNA parts with different reporters, express high $\mathrm{G}+\mathrm{C}$ (\%) biosynthetic genes, and demonstrate an initial proof of concept for combined transcription, translation, and biosynthesis of Streptomyces metabolic pathways in a single "one-pot" reaction.

KEYWORDS: cell-free synthetic biology, Streptomyces, natural products, in vitro transcription-translation, cell-free protein synthesis

\section{INTRODUCTION}

Streptomyces bacteria are environmental specialists (e.g., soil, marine, desert) that synthesize rich repertoires of natural products such as antibiotics. Much of this genetic information is locked up and cryptically regulated within biosynthetic gene clusters; regions of genomic DNA that harbor enzymes and other proteins (e.g., transporters, resistance markers). The key limitation in awakening these clusters for natural product discovery is silent gene expression and recalcitrant genetics. Traditional strategies to overcome this include genetic modification of the host organism to bypass native regulatory elements, and the "capture" of the cluster and expression in a heterologous host. ${ }^{1}$ But this can take several weeks to months to complete with varying levels of success: some cryptic clusters remain dormant due to obscure native regulation. Fundamental tools that aid these efforts are of major interest to the natural product community.

Prokaryotic cell-free coupled transcription-translation systems are emerging as a new tool for studying natural product biosynthesis. $^{2-9}$ Cell-free transcription-translation uses a crude cell-extract or purified ribosomes and translation factors, the PURE system, in a "one-pot" reaction. ${ }^{10,11}$ E. coli cellextracts, referred to as either TX-TL ${ }^{5,12,13}$ or cell-free protein synthesis (CFPS), ${ }^{4,14}$ are low-cost, straightforward to prepare, and provide high recombinant protein yields, of up to 2300 $\mu \mathrm{g} / \mathrm{mL}^{15}$ Moreover, metabolism is active, ${ }^{16}$ providing ATP regeneration, while amino acid pathways are dynamic, providing additional ATP (through L-glutamate). In addition, certain amino acids deplete and become limiting for protein synthesis. $^{17}$ In summary, TX-TL provides distinct oppor-

Received: November 17, 2020

Published: January 26, 2021 

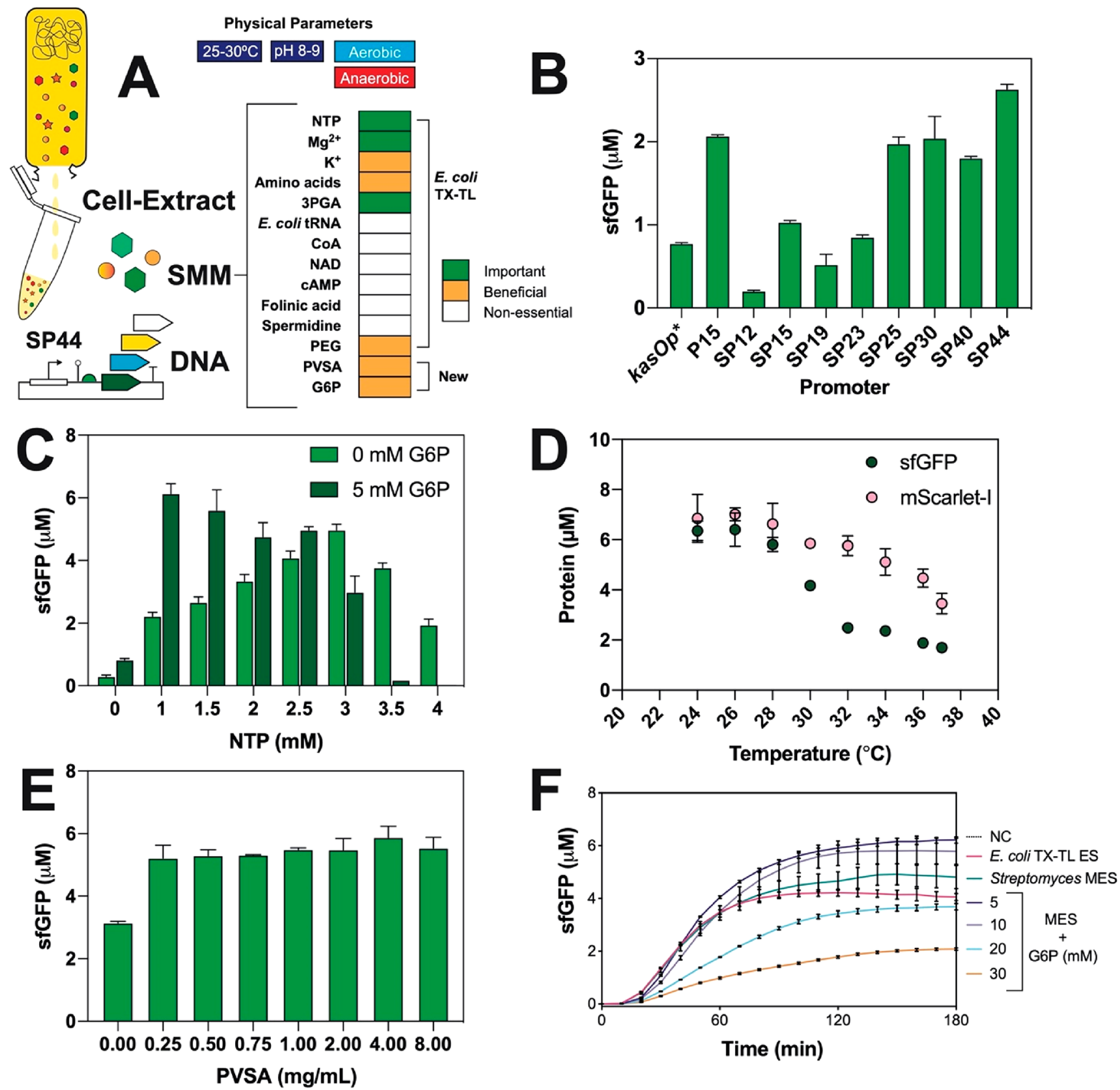

Figure 1. Overview of Streptomyces TX-TL optimization. (A) Outline of physical and biochemical parameters of Streptomyces TX-TL and SMM buffer system. Optimization of (B) promoter strength from Bai et al.; ${ }^{19}$ (C) primary energy source; (D) temperature; (E) PVSA; and (F) G6P. Error bars are representative of three technical measurements.

tunities for natural product biosynthesis: precursors for biosynthesis, direct control to feed precursors, short experimental time scales (4-24 h), and stable yields. Moreover, we and others have shown the potential for automation in cell-free synthesis. ${ }^{18-23}$ Specifically, we have screened up to 500 plasmid variants in $24 \mathrm{~h}^{23}$

While E. coli TX-TL and the PURE system are promising for natural product biosynthesis, ${ }^{2-4,9}$ E. coli has limited potential for studying biosynthetic gene clusters from Streptomyces, due to a number of genetic and metabolic differences. For example, the codon content between Streptomyces $(\sim 70 \% \mathrm{G}+\mathrm{C})$ and $E$. coli $(51 \% \mathrm{G}+\mathrm{C})$ is different, while the regulatory sequences that control transcription, post-transcription, and overall gene expression are distinct. Moreover, secondary metabolism in E. coli is not necessarily well-suited, and often requires further metabolic engineering. Notwithstanding, E. coli synthesis of heterologous proteins can result in poor expression and solubility. 5,24 Therefore, we anticipate that a dedicated Streptomyces TX-TL system for homologous protein synthesis, has several advantages for studying natural product biosynthesis. As a first step, we originally released a Streptomyces venezuelae DSM-40230 (ATCC 10712) TX-TL system, but this produced low protein yields $(36 \mu \mathrm{g} / \mathrm{mL})$ with high batchto-batch variability. We chose $S$. venezuelae ATCC 10712 since it is well-suited to synthetic biology. S. venezuelae ATCC 10712 is fast-growing ( $40 \mathrm{~min}$ doubling time) and grows dispersedly in liquid culture; most Streptomyces spp. have slower doubling times and clump in mycelial aggregates. Moreover, $S$. venezuelae has a range of synthetic biology tools ${ }^{25,26}$ and is an attractive host for industrial biotechnology. ${ }^{27,28}$ In parallel 
to our studies, the Jewett group ${ }^{7}$ also established a Streptomyces lividans CFPS system (yields $\sim 50 \mu \mathrm{g} / \mathrm{mL}$ ), which was further optimized. $^{29}$ A recent update to this system highlighted the need for adding individual purified translation factors ${ }^{8}$ to elevate protein synthesis up to $\sim 400 \mu \mathrm{g} / \mathrm{mL}$.

On this basis, we rationalized that protein synthesis, in our original S. venezuelae TX-TL system, could be limited by the use of an energy solution derived for an optimal E. coli TX-TL protocol. ${ }^{12}$ For a review of the biochemical role and origin of cell-free energy solutions, we refer the reader to Dopp et al. ${ }^{30}$ In brief, TX-TL requires a cell-extract, a primary and secondary energy source, amino acids, cofactors, molecular crowding agents, and additives (e.g., $\mathrm{Mg}^{2+}$, spermidine, folinic acid, tRNA) to support protein synthesis from a template DNA sequence. Some of these biochemicals are present in the cellextract but may be rate-limiting. The energy source is composed of nucleotide triphosphates to drive initial mRNA and protein synthesis (primary energy source) and commonly 3-phosphoglyceric acid (3-PGA) or phosphoenolpyruvate (PEP) as the secondary energy source. 3-PGA or PEP provide ATP regeneration to leverage extended protein synthesis. Potentially, primary metabolism could be activated in TX-TL to provide reducing equivalents (e.g., $\mathrm{NADH}, \mathrm{FADH}$ ), extra energy, and building blocks (e.g., amino acids, malonyl-CoA) for natural product biosynthetic pathways, as shown in cellextract metabolic engineering. ${ }^{31}$ In this work, we focus on upgrading our $S$. venezuelae system to elevate protein synthesis. We also demonstrate its broader potential for cell-free synthetic biology, namely, for characterizing DNA parts and activating some model biosynthetic pathways. To achieve this, we made some simple modifications to the system, allowing yields of up to $266 \mu \mathrm{g} / \mathrm{mL}$ of expressed recombinant proteins. We also demonstrate combined transcription-translation and biosynthesis of some example natural product pathways, namely, melanin and haem biosynthesis. We report an easyto-follow protocol that simply requires three components: DNA, cell-extract, and a master mix that we describe in detail. We believe this generic Streptomyces TX-TL toolkit will be of broad interest to the natural product community, complementing experimental wet-lab tools for genome mining studies.

\section{RESULTS AND DISCUSSION}

A High-Yield Streptomyces TX-TL Protocol. To provide an improved Streptomyces TX-TL toolkit for synthesis of high $\mathrm{G}+\mathrm{C}(\%)$ genes and pathways from Streptomyces spp. and related genomes, a key priority was to optimize protein production. Also, a straightforward protocol with minimal batch variation was essential, for ease of repeatability. Since bacterial transcription and translation is coupled, either these steps, physical parameters, or components from the energy solution, limit overall TX-TL activity. Therefore, to keep our protocol streamlined, we made the following changes: promoter strength, energy solution, ATP regeneration, and RNase inhibition. In doing so, we obtained a high-yield protocol with minimal variation between different cell-extract batches (Figure 1A).

Promoter Strength. Previously, we used the kasOp* promoter to drive mRNA synthesis in Streptomyces TX-TL. This yielded up to $1.3 \mu \mathrm{M}(36 \mu \mathrm{g} / \mathrm{mL})$ of the model superfolder green fluorescence protein (sfGFP) in our previous work. ${ }^{5}$ Promoter strength is a key limiting factor in heterologous expression systems. $\mathrm{kasOp}^{*}$ is a strong Streptomyces constitutive promoter, originally derived from the $k a s O / c p k O / s c o 6280$ promoter, with core- 35 and -10 boxes of TTGACN and TAGART, respectively. ${ }^{32}$ The kasOp* promoter is active in a range of Streptomyces spp. through the endogenous RNA polymerases and HrdB house-keeping Sigma factor. ${ }^{32}$ Bai et al. developed a synthetic promoter library based around $\mathrm{kasO}^{*}$, using fluorescence-activated cell sorting (FACS) to quantity S. venezuelae protoplasts. ${ }^{25}$ This included the isolation of a synthetic promoter 44 (SP44), which is 1.87 -fold stronger than kasOp*. ${ }^{25}$ We used Streptomyces TX-TL to test a panel of promoters developed by Bai et al., with SP44 being the strongest ( $2.63 \mu \mathrm{M}$ sfGFP) and 2.2-fold more active than $\mathrm{kasOp}^{*}$ (Figure 1B). We also repeated this across four independent cell-extract batches, but still observed strong batch variation. However, SP44 provided a stronger reporter plasmid to continue the optimization process.

Energy Solution. Next, we focused on developing a minimal energy solution (MES) to identify any nonessential components. The standard E. coli TX-TL energy solution used previously, ${ }^{5}$ is composed of HEPES buffer, ions (e.g., Mgglutamate, K-glutamate), nucleotide triphosphates (NTPs ATP, GTP, CTP, and UTP), secondary energy source [typically 3-phosphoglyceric acid (3-PGA) or phosphoenolpyruvate (PEP)], amino acids, molecular crowding agent, and a number of additives. ${ }^{14}$ To establish a MES for Streptomyces TX-TL, we first eliminated a number of nonessential components from the energy solution. This included coenzyme A, tRNA (E. coli), NAD, cAMP, folinic acid, and spermidine (Figure S1A). While we did initially observe a positive response with cAMP, after several repeats in batches, this effect was not repeatable. For the HEPES buffer component, this was noninhibitory $(10-100 \mathrm{mM})$ and provided optimum activity between $\mathrm{pH} 8-9$ (Figure S1B). For the secondary energy source, we found 3-PGA was essential; the removal of 3-PGA decreased sfGFP synthesis by $98 \%$ (Figure S1C). We tried to replace 3-PGA with alternative secondary energy sources but observed only minimal activity: maltose ( 0.13 $\mu \mathrm{M})$, sucrose $(0.15 \mu \mathrm{M})$, and pyruvate $(0.17 \mu \mathrm{M})$. Other potential sources such as glucose (with phosphate), PEP, and succinate were inactive (Figure S1C). 3-PGA is the preferred secondary energy source in a range of nonmodel cell-extract hosts, ${ }^{33}$ due to its chemical stability and high energy potential, with an optimum concentration of $30 \mathrm{mM}$ (Figure S1D). For the primary energy source (NTPs), there was some basal activity without additional NTPs, but addition of $3 \mathrm{mM}$ ATP/ GTP and $1.5 \mathrm{mM}$ CTP/UTP provided peak activity (Figure S1E). Surprisingly, the removal of amino acids only decreased sfGFP synthesis by $45 \%$, with $0.5-1.5 \mathrm{mM}$ amino acids providing peak activity (data not shown). For a $\mathrm{Mg}$ screen, we found that $\mathrm{MgCl}_{2}, \mathrm{Mg}$-glutamate, or $\mathrm{Mg}$-acetate were all active (Figure S1F), while high levels of K-glutamate (150-200 mM) stimulated increased sfGFP synthesis (Figure S1F). This is possibly due to additional ATP regeneration via entry of $\alpha$ ketoglutarate into the TCA cycle, as previously shown. ${ }^{34}$ Lastly, while we observed reasonable activity without PEG, 1\% $(\mathrm{w} / \mathrm{v})$ PEG $6 \mathrm{~K}$ was optimum, providing a $44 \%$ rise in activity (Figure S1G). However, it is desirable to omit PEG for downstream natural product analytical purposes (e.g., LCMS). Finally, on the basis of these observations, we optimized our basic Streptomyces TX-TL MES system by individually finetuning the concentration of its core components (3-PGA, NTPs), while leaving DNA (40 $\mathrm{nM}), \mathrm{Mg}$-glutamate (4 mM), K-glutamate $(150 \mathrm{mM})$, amino acids $(1.25 \mathrm{mM})$, and PEG 6K 

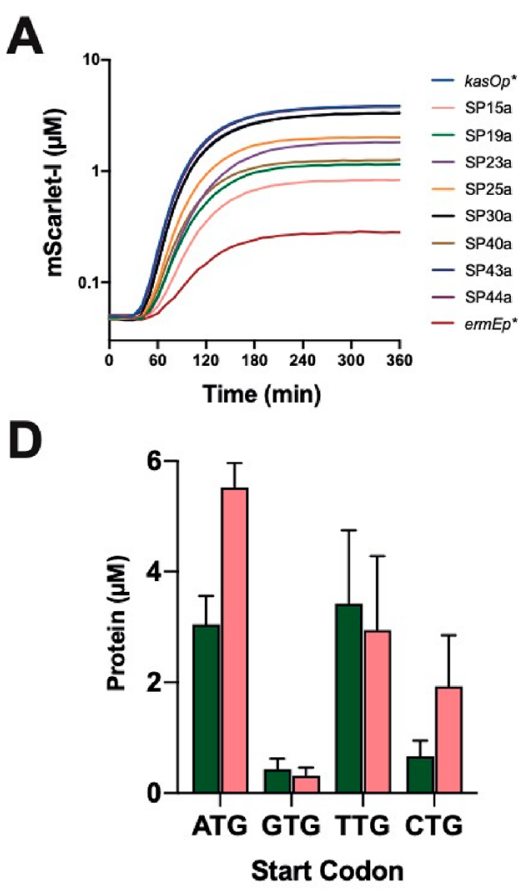

B

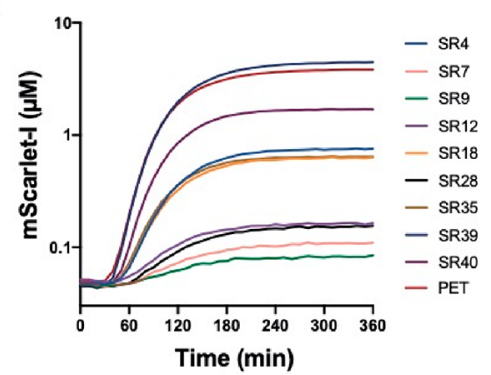

E

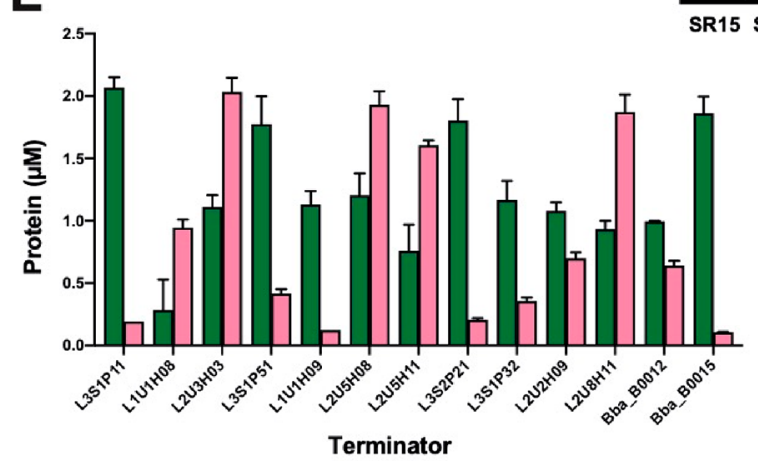

$\operatorname{sfGFP}(\mu M)$

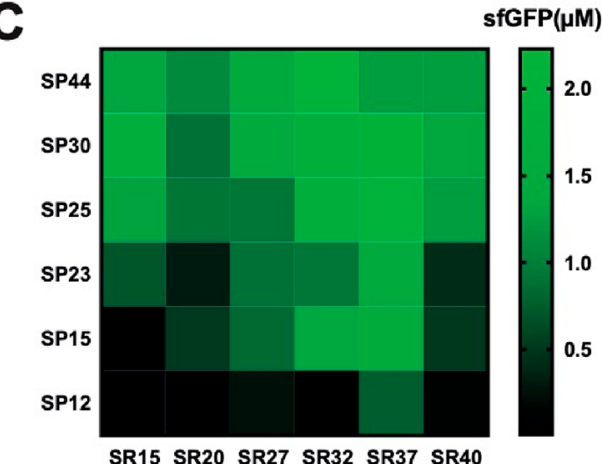

Figure 2. Part characterization of Streptomyces regulatory elements: (A) Promoter-R15 capsid RBS-mScarlet-I; (B) kasOp*-RBS-mScarlet-I; (C) Promoter-RBS-sfGFP combinations; (D) variable start codons (with sfGFP and mScarlet-I); and (E) variable Rho-independent terminators from Chen et al. ${ }^{34}$ For terminator plasmid design, see Moore et al. ${ }^{38} 40 \mathrm{nM}$ plasmid DNA was incubated in the optimized reaction conditions at $28{ }^{\circ} \mathrm{C}$ as a technical triplicate repeat and repeated on two separate days. Unless otherwise stated, the SP44 promoter, PET RBS and Bba_B0015 were used in constructs, assembled into either pTU1-A (E. coli) or pSF-1 (E. coli and Streptomyces shuttle vector). Error bars are representative of three technical measurements.

(1\%) constant. 3-PGA was most optimum at $30 \mathrm{mM}$, while the NTP level (ratio of 2:1 ATP/GTP:CTP/UTP), showed biphasic activity, peaking at $3 \mathrm{mM}$ ATP/GTP, with full inhibition at $4 \mathrm{mM}$. Specific data on Mg-glutamate and $\mathrm{K}$ glutamate optimization with four different cell-extract batches is presented in Figure S2. As a combined result of this optimization process, sfGFP synthesis was increased to $4 \mu \mathrm{M}$, representing a $52 \%$ increase.

Additional ATP Regeneration Pathways. In a previous study, Caschera et al. highlighted that other glycolytic enzymes function in E. coli TX-TL, using the disaccharide maltose (or maltodextrin) combined with 3-PGA. This method extended protein synthesis up to $10 \mathrm{~h}$, through inorganic phosphate recycling. ${ }^{15}$ We investigated whether this part of the metabolism is functional in Streptomyces TX-TL. Therefore, we tested the Streptomyces MES system (with 3-PGA) with maltose, glucose, glucose-6-phosphate (G6P), or fructose-1,6phosphate (F16P). Interestingly, maltose, glucose, Glc6P, and F16P all prolonged the length of Streptomyces TX-TL activity from 2 to $3 \mathrm{~h}$. This was maximal with $5 \mathrm{mM}$ Glc6P and $30 \mathrm{mM}$ 3-PGA (Figure 1C), at an optimum temperature of between 24 and $28{ }^{\circ} \mathrm{C}$ (Figure 1D). All together we observed a 59\% increase in sfGFP synthesis to $6.37 \mu \mathrm{M}$, but lower levels of $\mathrm{NTP}$ are required (Figure $1 \mathrm{C}$ ) - equivalent to $1 \mathrm{mM} \mathrm{ATP/}$ GTP and $0.5 \mathrm{mM} \mathrm{CTP/UTP.} \mathrm{We} \mathrm{speculate} \mathrm{this} \mathrm{could} \mathrm{be}$ related to ATP regulation of the glycolytic enzymes (e.g., hexokinase, fructokinase), leading to rapid depletion of ATP and inhibition of protein synthesis. However, this requires further investigation as there is limited literature on specific glycolytic enzymes from Streptomyces.

RNase Inhibition. As a final addition to the system, we tested the effect of the inexpensive RNase inhibitor, polyvinylsulfonic acid (PVSA). Recently, PVSA, an RNAmimetic, was shown to improve mRNA stability in E. coli TXTL, but did not increase protein synthesis. ${ }^{35}$ In Streptomyces TX-TL, $1 \mathrm{mg} / \mathrm{mL}$ PVSA increased sfGFP synthesis up to 5.87 $\mu \mathrm{M}$, in the basic MES system (Figure $1 \mathrm{E}$ ). However, while we observed individual improvements with either the PVSA RNase inhibitor or the blended G6P/3-PGA secondary energy source, in combination, there was no significant additive effect with PVSA and G6P/3-PGA together. This suggested that other rate-limiting factors are at play.

In summary, we have made a specific energy solution for Streptomyces TX-TL with an overall 6-fold improvement in the system. This is attributed to the combined use of 3PGA and G6P as secondary energy sources and a stronger promoter system. Furthermore, we find this can be combined into a single Streptomyces master mix (SMM) solution, further streamlining the reaction process. With this simple modification, the TX-TL reaction requires three single components that minimize batch variation: SMM solution, plasmid DNA, and the cell-extract. Next, we sought to demonstrate the use of this simplified system for the testing of plasmid tools and regulatory elements for Streptomyces synthetic biology.

Cell-Free Characterization of Streptomyces Genetic Tools for Synthetic Biology. It is highly desirable to characterize standard DNA parts using rapid and iterative design-build-test-learn cycles, the central paradigm of synthetic biology. For Streptomyces and related strains, either conjugation or protoplast transformation is typically used to transfer self-replicating and integrative plasmids for the testing of DNA parts for Streptomyces synthetic biology. ${ }^{25,26,32}$ DNA parts are small modular regulatory elements (e.g., promoter, insulator, tags, RBS, ORF, terminator) that facilitate down- 

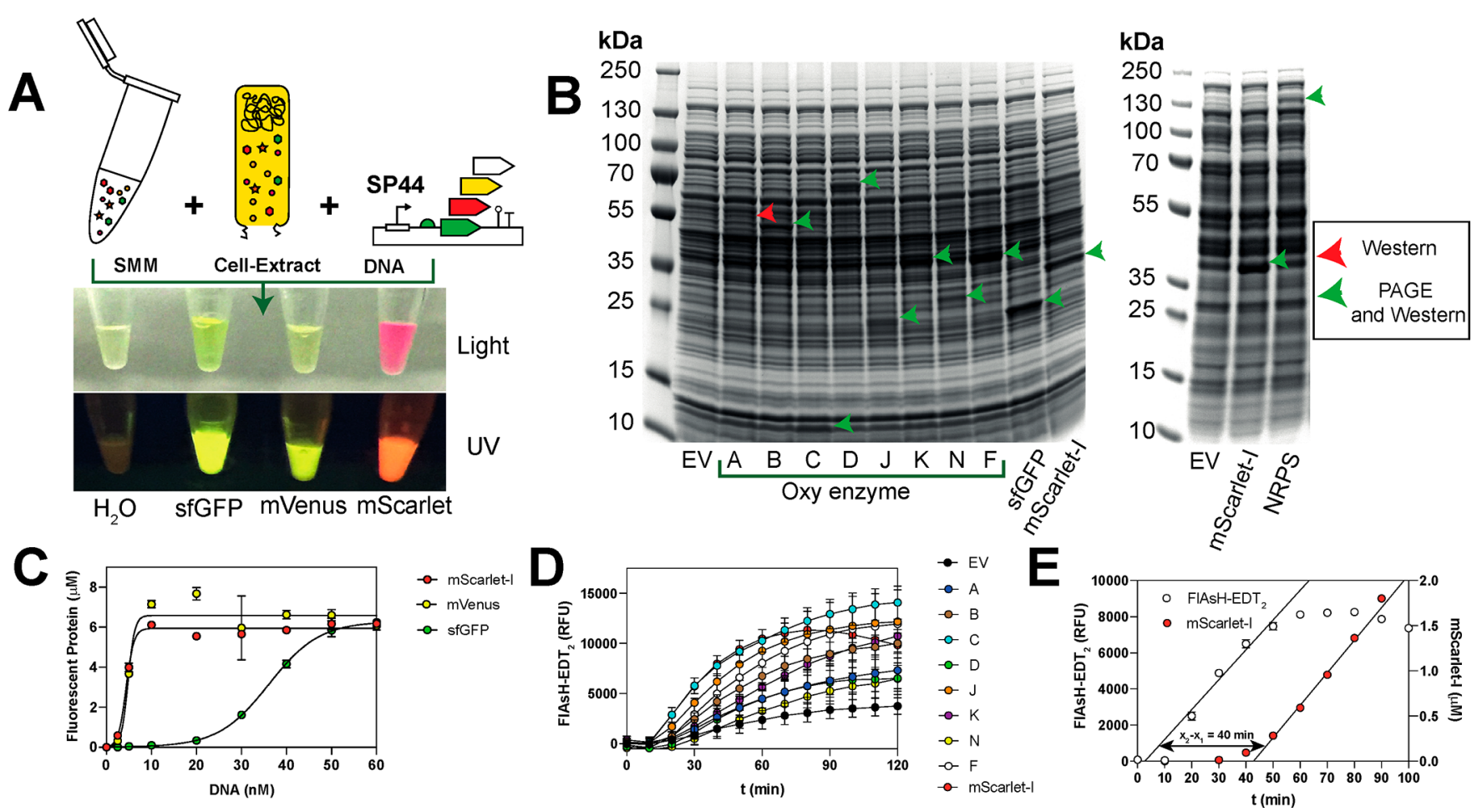

Figure 3. Robust and high-yield synthesis of high G+C (\%) genes. (A) Synthesis of codon-optimized fluorescence proteins. (B) Denaturing PAGE of oxytetracycline biosynthetic proteins, fluorescence proteins, and a representative NRPS (NH08_RS0107360 from S. rimosus). (C) Saturation of protein synthesis for sfGFP, mVenus, and mScarlet-I with increasing DNA concentrations. (D) Real-time detection of protein synthesis with Cterminal FlAsH-EDT 2 tag system. (E) Estimation of $\mathrm{mScarlet}-\mathrm{I}$ maturation time with real-time measurement of immature and mature protein synthesis. Error bars are representative of three technical measurements.

stream combinatorial DNA assembly workflows (e.g., Golden Gate) for refactoring gene expression pathways. While there are different approaches to quantitate gene expression, ${ }^{26,36}$ Bai et al. ${ }^{25}$ recently applied a lysozyme method, to study single-cell gene expression quantitation of S. venezuelae ATCC 10712 protoplasts using fluorescence-activated cell sorting.

We next tested the promoter and RBS elements from Bai et al. $^{25}$ in Streptomyces TX-TL, as well as two other important regulatory elements: alternative start codons ${ }^{36}$ and terminators. ${ }^{37}$ First, we built these DNA parts to be compatible with our previous DNA assembly method, EcoFlex. ${ }^{38}$ For this we had to modify the promoter consensus (prefix renamed, e.g., SP44a instead of SP44) to remove an internal BsmBI site to permit MoClo assembly. In addition, to provide comparative in vivo data, we built a new destination vector (cured of BsmBI and BsaI sites) from pAV-gapdh from Phelan et al. ${ }^{26}$ and renamed this StrepFlex (pSF1). pAV-gapdh is an integrative shuttle vector developed as a synthetic biology plasmid tool for S. venezuelae. ${ }^{26}$ First, for the promoter library ( $k a s O p^{*}, \mathrm{SP} 15 \mathrm{a}$, SP19a, SP23a, SP25a, SP30a, SP40a, SP44a, and ermEp*), we assembled this with the RiboJ insulator, R15 capsid RBS, mScarlet-I, and the Bba_B0015 terminator. For the RBS library, $\mathrm{kasOp}^{*}$ was used as the promoter. For the promoter variants, activity ranged from $5 \%(\mathrm{ermEp} *)$ to $100 \%(\mathrm{kasOp} *)$. In contrast to earlier results (Figure 1B), the range of activities for the BsmBI cured promoter variants were between 30 and $50 \%$ less active across the library. For the activity of the RBS variants, this ranged from $0.7 \%$ (SR9) to $117 \%$ (SR39) activity relative to the R15 capsid RBS (Figure 2B). We also tested two-dimensional promoter and RBS space with sfGFP (Figure 2C). Lastly, to provide in vivo data, we characterized the $\mathrm{mScarlet}-\mathrm{I}$ promoter and RBS plasmids (from Figure 2A,B) in
S. venezuelae ATCC 10712 (Figure S3) following the approach by Phelan et al. $^{26}$ Interestingly, there was some significant outliers in the RBS library. SR39 (along with the E. coli PETRBS) was the strongest RBS in contrast to SR40, which was unexpectedly weaker both in vitro and in vivo. In addition, SR4, an expected weak RBS, was strong in both in vitro and in vivo measurements (Figure 2A,B, Figure S3). This may reflect differences in the upstream $5^{\prime}$-untranslated $\left(5^{\prime}\right.$-UTR) region and the use of a different fluorescence reporter (mScarlet-I), in comparison to Bai et al. ${ }^{25}$ However, overall the promoter and RBS strengths characterized were broadly consistent with the original publication. ${ }^{25}$

Another important regulator of gene expression is the start codon. In most bacteria, ATG is the preferred codon for translation initiation through fMet-tRNA. Previously, Myronovskyi et al. used a $\beta$-glucuronidase (GUS) reporter to show that the TTG codon was stronger than ATG for translation initiation by almost 2-fold in both Streptomyces albus J1074 and Streptomyces sp. Tu6071. ${ }^{36}$ Using sfGFP and mScarlet-I as reporters, our findings suggest that, for $S$. venezuelae at least, ATG is equivalent in strength to TTG, followed by CTG and last GTG as the weakest (Figure 2C). This also likely changes with coding sequences and $5^{\prime}$-UTR. In comparison, for E. coli the order of strength goes as follows: ATG > GTG > TTG > CTG. ${ }^{39}$ We expect this differs due to high GC codon bias in Streptomyces. Despite the use of different experimental conditions, our results confirm that TTG is a strong alternative start codon and that GTG is weak. Nevertheless, the role of GTG in regulation is unclear and intriguing due its high frequency in Streptomyces genomes. ${ }^{40}$

To the best of our knowledge, no studies have so far reported the use of terminators for controlling pathway 


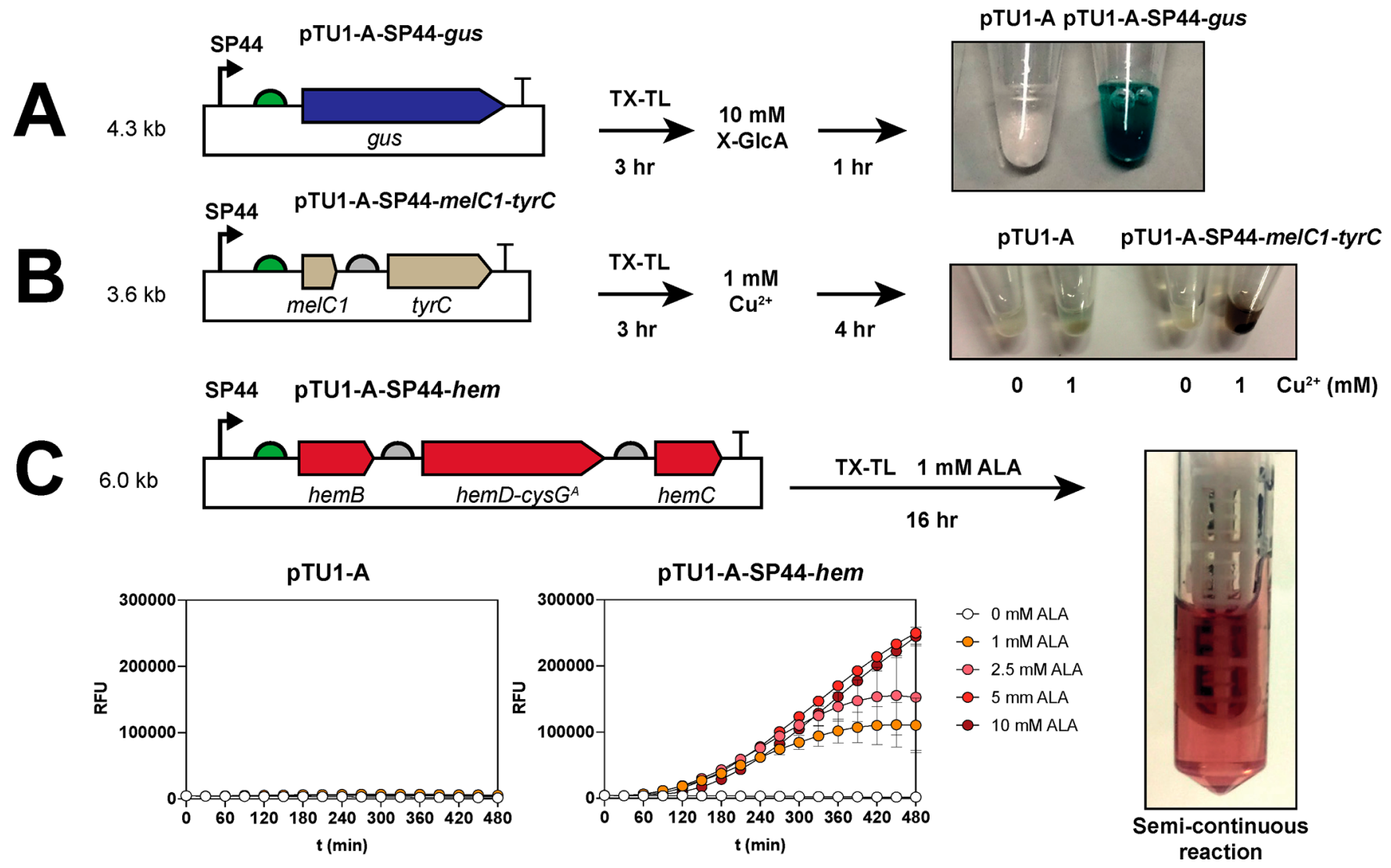

Figure 4. Streptomyces cell-free transcription, translation and biosynthesis. (A) Codon-optimized E. coli MG1655 GUS enzyme. (B) S. venezuelae DSM-40230 tyrosinase (TyrC) and copper metallochaperone (MelC1). (C) S. venezuelae DSM-40230 early stage haem biosynthetic pathway, $\mathrm{HemB}, \mathrm{HemD}-\mathrm{CysG}^{\mathrm{A}}$ and HemC. Addition of individual substrates and approximate time scales are indicated within the diagram. For details of batch and semicontinuous reaction conditions, please refer to methods. For a summary of the chemical intermediates, please see Figure S9. Melanin is a mixed family of pigments spontaneously produced from air oxidation of L-DOPA. Fluorescence error bars are representative of three technical measurements.

expression in Streptomyces. Using the same experimental format as we previously used in EcoFlex, ${ }^{38}$ we tested a selection of Rho-independent terminators from the iGEM catalogue (Bba_B0012, Bba_B0015) and from Chen et al. ${ }^{41}$ in $S$. venezuelae TX-TL (Figure $2 \mathrm{D}$ ). The latter terminators were designed to prevent repetition in DNA elements and protect against homologous recombination as previously highlighted. ${ }^{41,42}$ In summary, the activities we observed, strongly follow our previous observations in E. coli cell-free. ${ }^{38}$ For now, our TX-TL system demonstrates proof-of-concept data for prototyping DNA parts in Streptomyces. Rho-independent terminators may in future provide tools for refactoring metabolic pathways in engineered Streptomyces strains.

TX-TL synthesis of high G+C (\%) genes. Previously, we found our Streptomyces TX-TL system was most active with 40 $\mathrm{nM}$ of plasmid DNA, using the $k a s O p{ }^{*}$-sfGFP reporter, to saturate protein synthesis. ${ }^{35}$ In comparison to E. coli TX-TL, protein synthesis is saturated at around 5-10 $\mathrm{nM}$ of reporter DNA, which varies with different promoters and sigma factors. ${ }^{43}$ We questioned whether DNA degradation led to this discrepancy since most Streptomyces spp. degrade methylated plasmid DNA with endonucleases. ${ }^{44}$ To compare methylated and unmethylated plasmid DNA for methylationspecific endonucleases, we tested unmethylated and methylated SP44-sfGFP reporter plasmid in Streptomyces TX-TL. Interestingly, there was no major change in sfGFP synthesis between unmethylated and methylated plasmid DNA, across different DNA concentrations (Figure S4). We also tested relative plasmid DNA stability in S. venezuelae cell-extracts, with the standard MES energy solution, and incubated at different time-lengths, followed by re-extraction of the plasmid DNA (using the Qiagen plasmid DNA purification kit). The extracted plasmid DNA was then separated and visualized on a $1 \%(\mathrm{w} / \mathrm{v})$ agarose gel. This indicated that methylated plasmid DNA is stable, during the time $(0-4 \mathrm{~h})$ when TX-TL is active (Figure S4). Further to this, we tested linear DNA for exonuclease activity. To protect the coding sequences, we PCR amplified about $150-250$ bases upstream and downstream of the coding parts, using the standard SP44-sfGFP reporter plasmid. However, in the TX-TL reaction, linear DNA was 95\% less active than circular DNA, at $40 \mathrm{nM}$ of DNA (Figure S5). This suggests the $S$. venezuelae cell-extract has exonuclease activity, while endonuclease activity is minimal.

Since circular DNA degradation was not a limiting factor, we tested different fluorescent proteins (Figure $3 \mathrm{~A}$ ) to determine if the optimum plasmid DNA concentration for protein synthesis changes. First, we tested mVenus-I and mScarlet-I, combined with the strong SP44 promoter, and compared them to the SP44-sfGFP reporter. The maximum yields achieved for these three proteins were $6.48 \mu \mathrm{M}$ sfGFP $(174 \mu \mathrm{g} / \mathrm{mL}), 9.50$ $\mu \mathrm{M}$ mScarlet-I $(266 \mu \mathrm{g} / \mathrm{mL})$, and $7.72 \mu \mathrm{M}$ mVenus-I $(224 \mu \mathrm{g} /$ $\mathrm{mL})$. Interestingly, this was tested in the extract batches presented in Figure S2, where both SP44-mScarlet-I and SP44mVenus saturated protein synthesis with a lower DNA 
template $(10 \mathrm{nM})$ than SP44-sfGFP (50 nM) (Figure 3B). This was surprising since the coding sequence of mVenus is $96 \%$ identical to sfGFP, with the exception of 30 mutations and an additional GTG (valine) at the second codon for mVenus-I. However, while the optimal sfGFP plasmid DNA concentration was $50 \mathrm{nM}$ in this experiment, consistent with our previous work, ${ }^{5}$ it was not consistent in all extract batches (Figure S4B). This contrasting result likely relates to either a difference in mRNA stability or translation initiation rate between the batches. Since little is known about how Streptomyces $s p$. control protein synthesis, this topic alone merits a separate in-depth investigation.

Second, we tested the robustness of the system for other proteins from high $\mathrm{G}+\mathrm{C}(\%)$ genes (Figure $3 \mathrm{C})$. We expressed the oxytetracycline enzymes (OxyA, -B, $-\mathrm{C},-\mathrm{D},-\mathrm{J},-\mathrm{K},-\mathrm{N}$, and -T) from Streptomyces rimosus that were previously only detectable by Western blotting in our original publication, ${ }^{5}$ as well as three nonribosomal peptide synthetases (NRPS). The latter included the TxtA and TxtB NRPS enzymes from thaxtomin A biosynthesis in Streptomyces scabiei and an uncharacterized NRPS (NH08_RS0107360) from S. rimosus. Except for TxtA, most enzymes were discernible by either SDS-PAGE (Figure 3C), while for OxyA (47 kDa) and TxtB $(162 \mathrm{kDa})$, low levels $(<0.5 \mu \mathrm{M})$ were detected by Western blotting using an anti-Flag tag (data not shown). We also incorporated a C-terminal tetracysteine tag with the oxytetracycline enzymes and mScarlet-I, using the fluorogenic biarsenical dye fluorescein arsenical hairpin binder-ethanedithiol (FlAsH-EDT $\left.{ }_{2}\right)$, to measure real-time nascent protein synthesis (Figure 3D). Most oxytetracycline enzymes showed a significant increase in FlAsH-EDT 2 fluorescence $(P<0.05)$, peaking at $120 \mathrm{~min}$, with only OxyN producing the weakest response $(P=0.056)$. However, this was still clearly detectable by PAGE or Western. For mScarlet-I, the time-lag between the fluorescence signals for FlAsH-EDT2 (immature protein) and mScarlet-I (mature protein) allowed us to estimate a maturation time of $40 \mathrm{~min}$ for $\mathrm{mScarlet}-\mathrm{I}$ (Figure 3E). This is in close agreement to a literature value of $36 \mathrm{~min}$, calculated in vivo. ${ }^{45}$ In summary, our Streptomyces TX-TL system is robust for expression of high $\mathrm{G}+\mathrm{C}(\%)$ genes, incorporates multiple tools (e.g., tags, plasmid systems) and is comparable to other bacterial TX-TL systems.

Transcription, translation, and biosynthesis. The next step was to reconstitute a biosynthetic pathway in Streptomyces TX-TL system. Initially, to show the synthesis of a single enzyme and its activity, we selected the GUS reporter enzyme. We synthesized the enzyme in the TX-TL reaction from 40 $\mathrm{nM}$ SP44-gus, left for $4 \mathrm{~h}$ at $30^{\circ} \mathrm{C}$. The GUS enzyme showed a clear band on SDS-PAGE at the expected size of $68 \mathrm{kDa}$ (Figure S6). To test for GUS activity, an equal volume of the TX-TL extract, as well as a negative control reaction, was mixed with X-GlcA substrate in increasing concentrations (10, 25 , and $50 \mathrm{mg} / \mathrm{mL}$ ). Only the extract from the SP44-gus reaction developed a deep blue pigment within minutes, indicating strong GUS activity (Figure 4A).

Next, we selected two metabolic pathways to provide a further test for the TX-TL system. We selected two operons from $S$. venezuelae encoding the melanin and early stage haem biosynthetic pathways to provide a discernible output for testing (fluorescence and/or colorimetric). Also, both operons were selected from $S$. venezuelae, to improve expression in TX$\mathrm{TL}$ since the codon usage is adapted to this host.
Melanin is a natural pigment that absorbs ultraviolet (UV) light to protect cells from DNA damage. Recently, Matoba et al. studied the mechanism of tyrosinase and the role of the "caddie" protein from Streptomyces castaneoglobisporus HUT6202. ${ }^{46}$ Tyrosinase, TyrC, catalyzes the rate-limiting step in melanin biosynthesis. It oxidizes the phenol group (in L-tyrosine) into the orthro-quinone intermediate, which enters an autocatalytic cascade into the melanin pathway. TyrC is dicopper-dependent, with each $\mathrm{Cu}$ (II) atom coordinated by three His residues, facilitated by $\mathrm{MelC1}$, a small (12.8 kDa) metallochaperone. The $S$. venezuelae tyrosinase operon encodes both MelC1 and TyrC. After TX-TL with SP44-melC1-tyrC, denaturing PAGE shows clear synthesis of $\mathrm{TyrC}$ at approximately $34 \mathrm{kDa}$ (expected $31.4 \mathrm{kDa}$ ) although MelC1 was indistinguishable (Figure S7). In terms of activity, we observed brown pigment formation after $\sim 2 \mathrm{~h}$, only with the addition of $1 \mathrm{mM} \mathrm{CuCl}_{2}$ (Figure 4B). This indicates L-DOPA formation, which enters an autocatalytic cascade, leading to different melanin pigments. This suggests $\mathrm{TyrC}$ is active, despite the apparent absence of MelC1. Without the addition of $\mathrm{CuCl}_{2}$ or tyrosinase plasmid, the cell-extracts remained clear. Previously, Matoba et al. showed that insertion of $\mathrm{Cu}$ (II) into TyrC by MelC1 involves a transient interaction, and that MelC1 is unstable and forms aggregates difficult to detect with PAGE. ${ }^{46}$ Also, apo-TyrC is inactive with $\mathrm{Cu}(\mathrm{II})$ alone, which suggests that our TX-TL system supports the synthesis of both TyrC and MelC1.

Lastly, we tested a three-gene biosynthetic operon (hemChemD/cys $G^{A}$-hemB) that catalyzes the early stages of haem biosynthesis. ${ }^{47}$ This pathway was selected since it contains a known fluorescence reporter enzyme $\mathrm{CysG}^{\mathrm{A}},{ }^{48}$ a methyltransferase naturally fused as $\mathrm{HemD} / \mathrm{CysG}^{\mathrm{A}}$. We added a pTU1-ASP44-hemC-hemD/cys ${ }^{A}$-hemB (pTU1-A-SP44-hem) plasmid into the TX-TL reaction, as well as a negative control plasmid (pTU1-A), both with and without 5-aminolevulinic acid (5ALA), which is the substrate for the pathway. In the presence of pTU1-A and $1 \mathrm{mM}$ ALA, there was some minor background fluorescence (Figure 4C), which we expected since haem biosynthesis is essential. In contrast, with pTU1-A-SP44-hem and $1 \mathrm{mM}$ ALA, strong red fluorescence was generated, 20-fold higher than background levels in the control reaction (pTU1-A and $1 \mathrm{mM}$ ALA). For protein synthesis, while we could detect $\mathrm{HemB}(35 \mathrm{kDa})$ and $\mathrm{HemC}(38 \mathrm{kDa})$, the fusion protein $\mathrm{HemD} / \mathrm{CysG}^{\mathrm{A}}$ was less clear, with other major bands at the expected mass, $58.3 \mathrm{kDa}$ (Figure S6). To verify pathway function, we ran a semicontinuous reaction ${ }^{7}$ to facilitate purification by separating the haem intermediates from the cell-extract proteins (inset image in Figure 4C). Interestingly, LC-MS analysis detected the air-oxidized product of the HemD enzyme (uroporphyrinogen III, $837 \mathrm{~m} / z$ ), observed as a 6-electron oxidized uroporphyrin III (red fluorescent) intermediate at $831 \mathrm{~m} / z$, typical for these air-sensitive intermediates (Figures S8 and S9). Since uroporphyrinogen III is colorless and nonfluorescent, we tried to minimize oxygen levels in the TX-TL reaction using a layer of mineral oil in small-scale batch reactions. Surprisingly, the pigment and fluorescence still accumulated, suggesting that dissolved oxygen levels remain stable in the cell-extract. Interestingly, we also found the TX-TL reactions were still active for sfGFP and mScarlet-I synthesis (data not shown). This anaerobic activity potentially suggests that oxygen is not rate-limiting at the current level of protein synthesis activity and is sufficient for folding of the fluorescence proteins. Further investigation is 
needed to determine whether oxidative phosphorylation is active in Streptomyces TX-TL and whether this presents a bottleneck to overall ATP regeneration. In summary, these results show that our $S$. venezuelae TX-TL system can support the synthesis of at least three enzymes from plasmid DNA in a combined "one-pot" translation, translation, and enzymatic pathway.

\section{CONCLUSIONS}

Our study complements a recent surge in interest in the use of cell-free systems for the study of biosynthetic pathways. ${ }^{2,4,9,29}$ Here we wanted to expand the palette of plasmid tools for the further development of $S$. venezuelae as a synthetic biology chassis by developing an optimized streptomyces TX-TL toolkit. ${ }^{5,25-27}$ Our combined findings show at least a 6-fold improvement in protein synthesis over our original Streptomyces TX-TL system, using the wild-type $S$. venezuelae ATCC 10712 strain. It is likely genetic modifications that either limit RNA degradation or increase translation rates will improve this current system. Indeed, $\mathrm{Xu}$ et al. recently showed translation factors are a clear rate-limiting step for other Streptomyces cellfree systems. ${ }^{8}$ Finally, we demonstrate that the semicontinuous system permits reasonable milligram scale-up of biosynthetic metabolites and a clean route to purification and analysis. In conclusion, our results realize the early stage potential of Streptomyces cell-free for the study of synthetic biology for natural products. It provides a native prototyping environment for developing synthetic biology tools (e.g., promoters/RBS) and also for exploring biosynthetic pathways from these organisms.

\section{METHODS}

Molecular Biology. All plasmids were either prepared using EcoFlex cloning or by routine materials and methods, as previously described. ${ }^{41}$ For the PCR of high GC genes and operons, Q5 polymerase (NEB, UK) was used, using standard cycling or touchdown $\left(72-59{ }^{\circ} \mathrm{C}\right.$ annealing) and the addition of $5 \%(\mathrm{v} / \mathrm{v})$ DMSO. For tricky amplicons, the protocol was modified with an annealing time of $30 \mathrm{~s}$ and elongation temperature reduced to $68{ }^{\circ} \mathrm{C}$. The following bacterial strains were used: S. venezuelae DSM-40230 and E. coli DH10 $\beta$. Unmethylated plasmid DNA was prepared from an E. coli $\mathrm{dam}^{-} \mathrm{dcm}^{-}$mutant (C2925) obtained from NEB. Plasmids and oligonucleotides are listed in Tables S1-S4.

Preparation of Cell-Extracts. S. venezuelae ATCC 10712 was grown in GYM (prepared in distilled water). The cellextracts were prepared as described previously, ${ }^{5}$ with the exception that $\beta$-mercaptoethanol was removed from the wash buffers and replaced with $2 \mathrm{mM}$ dithiothreitol.

Energy Solution and Reaction Conditions. The reaction mixture contained $8 \mathrm{mg} / \mathrm{mL}$ cell-extract, $25 \mathrm{mM}$ HEPES, $1 \mathrm{mM}$ ATP, $1 \mathrm{mM}$ GTP, $0.5 \mathrm{mM}$ UTP, $0.5 \mathrm{mM}$ CTP, $30 \mathrm{mM}$ 3-PGA, $5 \mathrm{mM}$ glucose-6-phosphate, $1.5 \mathrm{mM}$ amino acids (1.25 mM L-leucine), $4 \mathrm{mM} \mathrm{Mg-glutamate,} 150 \mathrm{mM} \mathrm{K}$ glutamate, $1 \%(\mathrm{w} / \mathrm{v})$ PEG6K and $5 \mathrm{mg} / \mathrm{mL}$ PVSA. All reactions were incubated at $28{ }^{\circ} \mathrm{C}$, with $40 \mathrm{nM}$ pTU1-A-SP44sfGFP and the MES or SMM buffer system, unless otherwise stated. At least three technical repeats were prepared (for fluorescence measurements) and repeated with at least two independent cell-extract batches (from A6-A9) prepared on separate days. (See Table S6 for chemicals in the SMM buffer.)
Denaturing PAGE. A $40 \mu \mathrm{L}$ cell-free reaction $(30 \mu \mathrm{L}$ $\mathrm{SMM}+10 \mu \mathrm{L}$ plasmid DNA) was incubated in a $2 \mathrm{~mL}$ tube at $25-30{ }^{\circ} \mathrm{C}$ (no shaking) for $6 \mathrm{~h}$. To precipitate proteins, $1 \mathrm{~mL}$ of ice-cold $100 \%(\mathrm{v} / \mathrm{v})$ acetone was added. Samples were placed at $-20{ }^{\circ} \mathrm{C}$ for $30 \mathrm{~min}$, before centrifugation at $18000 \mathrm{~g}$, $4{ }^{\circ} \mathrm{C}$, for $10 \mathrm{~min}$. The supernatant was removed, and the pellet was washed with $1 \mathrm{~mL}$ of ice-cold $70 \%$ (v/v) acetone. Centrifugation and supernatant removal steps were then repeated. The pellet was air-dried, before resuspending in 30 $\mu \mathrm{L}$ of $\mathrm{ddH}_{2} \mathrm{O}$ and $10 \mu \mathrm{L}$ of $4 \mathrm{X}$ NuPAGE lithium dodecyl sulfate (LDS) sample buffer (ThermoFisher) and boiled at 100 ${ }^{\circ} \mathrm{C}$ for $5 \mathrm{~min}$. To ensure the pellet was solubilized, samples were aspirated with a pipet five times, and if necessary (a visible pellet remaining), left for an additional $5 \mathrm{~min}$ at $100^{\circ} \mathrm{C}$. An amount of $10-100 \mu \mathrm{g}$ of total protein was then separated with a $4-12 \%(\mathrm{v} / \mathrm{v})$ gradient Bis-Tris gel (ThermoFisher) run in an MES buffer system. Proteins were stained with InstantBlue (Generon) and destained with $\mathrm{ddH}_{2} \mathrm{O}$, and the images were recorded with the ChemiDoc XRS imaging system (Biorad).

TX-TL Fluorescence Measurements. Ten microliters of cell-free reactions was prepared in a 384-well black clear, Fbottom, low-binding plate (Greiner). Reactions were measured as a triplicate technical repeat and at least repeated with cellextracts prepared from two separate days. They were measured in a 384-well plate. The plate was sealed with aluminum film, SILVERseal (Greiner), and briefly centrifuged at $2000 \mathrm{~g}$ for 10 s. Real-time plate measurements were recorded in a CLARIOStar plate reader (BMG Labtech, Germany) at 30 ${ }^{\circ} \mathrm{C}$ with $10 \mathrm{~s}$ of shaking at $500 \mathrm{rpm}$ prior to measurements, using either standard filters (Omega) or monochromator settings (CLARIOStar). Purified sfGFP, mVenus-I and mScarlet-I standards were purified, as described previously, ${ }^{5}$ to estimate protein concentration during real-time fluorescence measurements.

Mass Spectrometry Analysis. TX-TL reactions were prepared as two components (A and B) in a semicontinuous reaction as follows: Component A: $100 \mu \mathrm{L}$ of standard TX-TL reaction, in the absence of PEG, was injected into a Thermo Scientific Pierce 3.5K MWCO 96-well microdialysis device. Component B: $1.5 \mathrm{~mL}$ of SMM solution with $1 \mathrm{mg} / \mathrm{mL}$ carbenicillin was placed in a $2.5 \mathrm{~mL}$ tube. The microdialysis cassette was placed inside the $2.5 \mathrm{~mL}$ tube and incubated at 30 ${ }^{\circ} \mathrm{C}$ for $24 \mathrm{~h}$ with shaking (1000 rpm). Samples were acidified with $1 \%(\mathrm{v} / \mathrm{v}) \mathrm{HCl}$, centrifuged at $18000 \mathrm{~g}$ for $25 \mathrm{~min}$ at room temperature. The supernatant was loaded onto a Sep-Pak C-18 (50 mg sorbent) solid-phase extraction cartridge (Waters), washed with $10 \mathrm{~mL}$ of $10 \%(\mathrm{v} / \mathrm{v})$ ethanol and eluted with 2 $\mathrm{mL}$ of $50 \%(\mathrm{v} / \mathrm{v})$ ethanol. All solutions were acidified with $1 \%$ $(\mathrm{v} / \mathrm{v}) \mathrm{HCl}$. Eluted samples were dried under vacuum at room temperature, using an Eppendorf Concentrator Plus. Samples were dissolved in $150 \mu \mathrm{L}$ of $1 \%(\mathrm{v} / \mathrm{v}) \mathrm{HCl}$ and centrifuged again at $18000 \mathrm{~g}$ for $25 \mathrm{~min}$ at room temperature. One microliter of supernatant was then analyzed by LC-MS, performed with an Agilent 1290 Infinity system with an online diode array detector in combination with a Bruker 6500 quadruple time-of-flight (Q-ToF) mass spectrometer. An Agilent Extend-C18 $2.1 \mathrm{~mm} \times 50 \mathrm{~mm}(1.8 \mu \mathrm{m}$ particle size $)$ column was used at a temperature of $40{ }^{\circ} \mathrm{C}$ with a buffer flow rate of $0.5 \mathrm{~mL} / \mathrm{min}$. LC was performed with a gradient of buffer A $[0.1 \%(\mathrm{v} / \mathrm{v})$ formic acid in water $]$ and buffer B $[0.1 \%$ $(\mathrm{v} / \mathrm{v})$ formic acid in acetonitrile]. Separation was achieved using $2 \%$ buffer B for $0.6 \mathrm{~min}$, followed by a linear gradient to 
$100 \%$ buffer B from $0.6-4.6 \mathrm{~min}$, which was held at $100 \%$ buffer B from $4.6-5.6 \mathrm{~min}$ followed by a return to $2 \%$ buffer $B$ from 5.6-6.6 $\mathrm{min}$, along with $1 \mathrm{~min}$ post-run. Spectra were recorded between a mass range of $50-1700 \mathrm{~m} / z$ at a rate of 10 spectra per second in positive polarity.

\section{ASSOCIATED CONTENT}

\section{SI Supporting Information}

The Supporting Information is available free of charge at https://pubs.acs.org/doi/10.1021/acssynbio.0c00581.

Additional methods, S. venezuelae ATCC 10712 promoter and RBS platereader characterization; list of plamids created in this study, oligonucleotides, annealing oligonucleotides, sequencing primers, promoter, RBS, and RiboJ parts, DNA sequences; additional figures (PDF)

\section{AUTHOR INFORMATION}

\section{Corresponding Authors}

Simon J. Moore - Centre for Synthetic Biology and Innovation and Department Section of Structural and Synthetic Biology, Department of Infectious Disease, Imperial College London, London SW7 2AZ, U.K.; School of Biosciences, University of Kent, Canterbury, Kent CT2 7NJ, U.K.; 이이이.org/00000002-1968-206X; Email: S.J.R.Moore@kent.ac.uk

Paul S. Freemont - Centre for Synthetic Biology and Innovation, Department Section of Structural and Synthetic Biology, Department of Infectious Disease, and UK Dementia Research Institute Care Research and Technology Centre, Imperial College London, London SW7 2AZ, U.K.; The London Biofoundry, Imperial College Translation \& Innovation Hub, London W12 OBZ, U.K.; (1) orcid.org/ 0000-0002-5658-8486; Email: p.freemont@imperial.ac.uk

\section{Authors}

Hung-En Lai - Centre for Synthetic Biology and Innovation and Department Section of Structural and Synthetic Biology, Department of Infectious Disease, Imperial College London, London SW7 2AZ, U.K.

Soo-Mei Chee - Department Section of Structural and Synthetic Biology, Department of Infectious Disease, Imperial College London, London SW7 2AZ, U.K.; The London Biofoundry, Imperial College Translation \& Innovation Hub, London W12 OBZ, U.K.

Ming Toh - Centre for Synthetic Biology and Innovation and Department Section of Structural and Synthetic Biology, Department of Infectious Disease, Imperial College London, London SW7 2AZ, U.K.

Seth Coode - School of Biosciences, University of Kent, Canterbury, Kent CT2 7NJ, U.K.

Kameshwari Chengan - School of Biosciences, University of Kent, Canterbury, Kent CT2 7NJ, U.K.

Patrick Capel - Warwick Integrative Synthetic Biology Centre, School of Life Sciences, University of Warwick, Coventry CV4 7AL, U.K.

Christophe Corre - Warwick Integrative Synthetic Biology Centre, School of Life Sciences, University of Warwick, Coventry CV4 7AL, U.K.

Emmanuel LC de los Santos - Warwick Integrative Synthetic Biology Centre, School of Life Sciences, University of Warwick, Coventry CV4 7AL, U.K.

Complete contact information is available at: https://pubs.acs.org/10.1021/acssynbio.0c00581

\section{Funding}

The author would like to acknowledge the following research support: EPSRC [EP/K038648/1] for S.J.M. as a PDRA with P.S.F.; Wellcome Trust sponsored ISSF fellowship for S.J.M. with P.S.F. at Imperial College London; Royal Society research

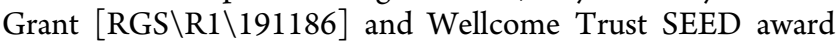
$[217528 / \mathrm{Z} / 19 / \mathrm{Z}]$ for S.J.M. at the University of Kent.

\section{Notes}

The authors declare no competing financial interest.

\section{ACKNOWLEDGMENTS}

The authors would like to thank Professor Jay Keasling (University of California) for providing the plasmid pAVgapdh.

\section{REFERENCES}

(1) Rutledge, P. J., and Challis, G. L. (2015) Discovery of Microbial Natural Products by Activation of Silent Biosynthetic Gene Clusters. Nat. Rev. Microbiol. 13 (8), 509-523.

(2) Khatri, Y., Hohlman, R. M., Mendoza, J., Li, S., Lowell, A. N., Asahara, H., and Sherman, D. H. (2020) Multicomponent Microscale Biosynthesis of Unnatural Cyanobacterial Indole Alkaloids. ACS Synth. Biol. 9 (6), 1349-1360.

(3) Zhuang, L., Huang, S., Liu, W.-Q., Karim, A. S., Jewett, M. C., and $\mathrm{Li}, \mathrm{J} .(2020)$ Total in vitro Biosynthesis of the Nonribosomal Macrolactone Peptide Valinomycin. Metab. Eng. 60, 37-44.

(4) Goering, A. W., Li, J., McClure, R. A., Thomson, R. J., Jewett, M. C., and Kelleher, N. L. (2017) in vitro Reconstruction of Nonribosomal Peptide Biosynthesis Directly from DNA Using CellFree Protein Synthesis. ACS Synth. Biol. 6 (1), 39-44.

(5) Moore, S. J., Lai, H.-E., Needham, H., Polizzi, K. M., and Freemont, P. S. (2017) Streptomyces Venezuelae TX-TL - a next Generation Cell-Free Synthetic Biology Tool. Biotechnol. J. 12 (4), 1600678 .

(6) Ozaki, T., Yamashita, K., Goto, Y., Shimomura, M., Hayashi, S. Asamizu, S., Sugai, Y., Ikeda, H., Suga, H., and Onaka, H. (2017) Dissection of Goadsporin Biosynthesis by in vitro Reconstitution Leading to Designer Analogues Expressed in vivo. Nat. Commun. 8, 14207.

(7) Li, J., Wang, H., Kwon, Y. C., and Jewett, M. C. (2017) Establishing a High Yielding Streptomyces-Based Cell-Free Protein Synthesis System. Biotechnol. Bioeng. 114 (6), 1343-1353.

(8) Xu, H., Liu, W.-Q., and Li, J. (2020) Translation Related Factors Improve the Productivity of a Streptomyces-Based Cell-Free Protein Synthesis System. ACS Synth. Biol. 9 (5), 1221-1224.

(9) Siebels, I., Nowak, S., Heil, C. S., Tufar, P., Cortina, N. S., Bode, H. B., and Grininger, M. (2020) Cell-Free Synthesis of Natural Compounds from Genomic DNA of Biosynthetic Gene Clusters. ACS Synth. Biol. 9 (9), 2418-2426.

(10) Kuruma, Y., and Ueda, T. (2015) The PURE System for the Cell-Free Synthesis of Membrane Proteins. Nat. Protoc. 10 (9), 13281344.

(11) Lavickova, B., and Maerkl, S. J. (2019) A Simple, Robust, and Low-Cost Method To Produce the PURE Cell-Free System. ACS Synth. Biol. 8 (2), 455-462.

(12) Sun, Z. Z., Hayes, C. A., Shin, J., Caschera, F., Murray, R. M., and Noireaux, V. (2013) Protocols for Implementing an Escherichia Coli Based TX-TL Cell-Free Expression System for Synthetic Biology. J. Visualized Exp. 50762 (79), e50762.

(13) Takahashi, M. K., Chappell, J., Hayes, C. A., Sun, Z. Z., Kim, J., Singhal, V., Spring, K. J., Al-Khabouri, S., Fall, C. P., Noireaux, V., Murray, R. M., and Lucks, J. B. (2015) Rapidly Characterizing the Fast Dynamics of RNA Genetic Circuitry with Cell-Free Transcription-Translation (TX-TL) Systems. ACS Synth. Biol. 4 (5), 503515. 
(14) Gregorio, N. E., Levine, M. Z., and Oza, J. P. (2019) A User's Guide to Cell-Free Protein Synthesis. Methods Protoc. 2 (1), 24.

(15) Caschera, F., and Noireaux, V. (2014) Synthesis of $2.3 \mathrm{Mg} / \mathrm{Ml}$ of Protein with an All Escherichia coli Cell-Free TranscriptionTranslation System. Biochimie 99 (1), 162-168.

(16) Jewett, M. C., and Swartz, J. R. (2004) Mimicking the Escherichia coli Cytoplasmic Environment Activates Long-Lived and Efficient Cell-Free Protein Synthesis. Biotechnol. Bioeng. 86 (1), 1926.

(17) Zawada, J. F., Yin, G., Steiner, A. R., Yang, J., Naresh, A., Roy, S. M., Gold, D. S., Heinsohn, H. G., and Murray, C. J. (2011) Microscale to Manufacturing Scale-up of Cell-Free Cytokine Production-a New Approach for Shortening Protein Production Development Timelines. Biotechnol. Bioeng. 108 (7), 1570-1578.

(18) Borkowski, O., Koch, M., Zettor, A., Pandi, A., Batista, A. C., Soudier, P., and Faulon, J.-L. (2020) Large Scale Active-LearningGuided Exploration for in vitro Protein Production Optimization. Nat. Commun. 11 (1), 1872.

(19) Quast, R. B., Kortt, O., Henkel, J., Dondapati, S. K., Wüstenhagen, D. A., Stech, M., and Kubick, S. (2015) Automated Production of Functional Membrane Proteins Using Eukaryotic CellFree Translation Systems. J. Biotechnol. 203, 45-53.

(20) Karim, A. S., Heggestad, J. T., Crowe, S. A., and Jewett, M. C. (2018) Controlling Cell-Free Metabolism through Physiochemical Perturbations. Metab. Eng. 45, 86-94.

(21) McManus, J. B., Emanuel, P. A., Murray, R. M., and Lux, M. W. (2019) A Method for Cost-Effective and Rapid Characterization of Engineered T7-Based Transcription Factors by Cell-Free Protein Synthesis Reveals Insights into the Regulation of T7 RNA Polymerase-Driven Expression. Arch. Biochem. Biophys. 674, 108045.

(22) Marshall, R., and Noireaux, V. (2019) Quantitative Modeling of Transcription and Translation of an All-E. coli Cell-Free System. Sci. Rep. 9 (1), 11980.

(23) Moore, S. J., MacDonald, J. T., Wienecke, S., Ishwarbhai, A., Tsipa, A., Aw, R., Kylilis, N., Bell, D. J., McClymont, D. W., Jensen, K., Polizzi, K. M., Biedendieck, R., and Freemont, P. S. (2018) Rapid Acquisition and Model-Based Analysis of Cell-Free TranscriptionTranslation Reactions from Nonmodel Bacteria. Proc. Natl. Acad. Sci. U. S. A. 115 (19), E4340-E4349.

(24) Cheng, Q., Xiang, L., Izumikawa, M., Meluzzi, D., and Moore, B. S. (2007) Enzymatic Total Synthesis of Enterocin Polyketides. Nat. Chem. Biol. 3 (9), 557-558.

(25) Bai, C., Zhang, Y., Zhao, X., Hu, Y., Xiang, S., Miao, J., Lou, C., and Zhang, L. (2015) Exploiting a Precise Design of Universal Synthetic Modular Regulatory Elements to Unlock the Microbial Natural Products in Streptomyces. Proc. Natl. Acad. Sci. U. S. A. 112 (39), 12181-12186.

(26) Phelan, R. M., Sachs, D., Petkiewicz, S. J., Barajas, J. F., BlakeHedges, J. M., Thompson, M. G., Reider Apel, A., Rasor, B. J., Katz, L., and Keasling, J. D. (2017) Development of Next Generation Synthetic Biology Tools for Use in Streptomyces venezuelae. ACS Synth. Biol. 6 (1), 159-166.

(27) Phelan, R. M., Sekurova, O. N., Keasling, J. D., and Zotchev, S. B. (2015) Engineering Terpene Biosynthesis in Streptomyces for Production of the Advanced Biofuel Precursor Bisabolene. ACS Synth. Biol. 4 (4), 393-399.

(28) Han, A. R., Park, J. W., Lee, M. K., Ban, Y. H., Yoo, Y. J., Kim, E. J., Kim, E., Kim, B. G., Sohng, J. K., and Yoon, Y. J. (2011) Development of a Streptomyces venezuelae-Based Combinatorial Biosynthetic System for the Production of Glycosylated Derivatives of Doxorubicin and Its Biosynthetic Intermediates. Appl. Environ. Microbiol. 77 (14), 4912-4923.

(29) Li, J., Wang, H., and Jewett, M. C. (2018) Expanding the Palette of Streptomyces-Based Cell-Free Protein Synthesis Systems with Enhanced Yields. Biochem. Eng. J. 130, 29-33.

(30) Dopp, B. J. L., Tamiev, D. D., and Reuel, N. F. (2019) CellFree Supplement Mixtures: Elucidating the History and Biochemical Utility of Additives Used to Support in Vitro Protein Synthesis in E. coli Extract. Biotechnol. Adv. 37 (1), 246-258.
(31) Dudley, Q. M., Nash, C. J., and Jewett, M. C. (2019) Cell-Free Biosynthesis of Limonene Using Enzyme-Enriched Escherichia coli Lysates. Synth. Biol. 4 (1), ysz003.

(32) Wang, W., Li, X., Wang, J., Xiang, S., Feng, X., and Yang, K. (2013) An Engineered Strong Promoter for Streptomycetes. Appl. Environ. Microbiol. 79 (14), 4484-4492.

(33) Yim, S. S., Johns, N. I., Park, J., Gomes, A. L., McBee, R. M., Richardson, M., Ronda, C., Chen, S. P., Garenne, D., Noireaux, V., and Wang, H. H. (2019) Multiplex Transcriptional Characterizations across Diverse Bacterial Species Using Cell-Free Systems. Mol. Syst. Biol. 15 (8), e8875.

(34) Jewett, M. C., Calhoun, K. A., Voloshin, A., Wuu, J. J., and Swartz, J. R. (2008) An Integrated Cell-Free Metabolic Platform for Protein Production and Synthetic Biology. Mol. Syst. Biol. 4 (220), 220

(35) Earl, C. C., Smith, M. T., Lease, R. A., and Bundy, B. C. (2018) Polyvinylsulfonic Acid: A Low-Cost RNase Inhibitor for Enhanced RNA Preservation and Cell-Free Protein Translation. Bioengineered 9 (1), 90-97.

(36) Myronovskyi, M., Welle, E., Fedorenko, V., and Luzhetskyy, A. (2011) $\beta$-Glucuronidase as a Sensitive and Versatile Reporter in Actinomycetes. Appl. Environ. Microbiol. 77 (15), 5370-5383.

(37) Temme, K., Zhao, D., and Voigt, C. A. (2012) Refactoring the Nitrogen Fixation Gene Cluster from Klebsiella oxytoca. Proc. Natl. Acad. Sci. U. S. A. 109 (18), 7085-7090.

(38) Moore, S. J., Lai, H.-E., Kelwick, R. J. R., Chee, S. M., Bell, D. J., Polizzi, K. M., and Freemont, P. S. (2016) EcoFlex: A Multifunctional MoClo Kit for E. coli Synthetic Biology. ACS Synth. Biol. 5 (10), 1059-1069.

(39) Hecht, A., Glasgow, J., Jaschke, P. R., Bawazer, L. A., Munson, M. S., Cochran, J. R., Endy, D., and Salit, M. (2017) Measurements of Translation Initiation from All 64 Codons in E. coli. Nucleic Acids Res. 45 (7), 3615-3626.

(40) Bibb, M. J., Molle, V., and Buttner, M. J. (2000) Sigma(BldN), an Extracytoplasmic Function RNA Polymerase Sigma Factor Required for Aerial Mycelium Formation in Streptomyces coelicolor A3(2). J. Bacteriol. 182 (16), 4606-4616.

(41) Chen, Y.-J., Liu, P., Nielsen, A. A. K., Brophy, J. A. N., Clancy, K., Peterson, T., and Voigt, C. A. (2013) Characterization of 582 Natural and Synthetic Terminators and Quantification of Their Design Constraints. Nat. Methods 10 (7), 659-664.

(42) Nielsen, A. A. K., Der, B. S., Shin, J., Vaidyanathan, P., Paralanov, V., Strychalski, E. A., Ross, D., Densmore, D., and Voigt, C. A. (2016) Genetic Circuit Design Automation. Science 352 (6281), aac7341.

(43) Garamella, J., Marshall, R., Rustad, M., and Noireaux, V. (2016) The All E. coli TX-TL Toolbox 2.0: A Platform for Cell-Free Synthetic Biology. ACS Synth. Biol. 5 (4), 344-355.

(44) González-Cerón, G., Miranda-Olivares, O. J., and ServínGonzález, L. (2009) Characterization of the Methyl-Specific Restriction System of Streptomyces Coelicolor A3(2) and of the Role Played by Laterally Acquired Nucleases. FEMS Microbiol. Lett. 301 (1), 35-43.

(45) Bindels, D. S., Haarbosch, L., van Weeren, L., Postma, M., Wiese, K. E., Mastop, M., Aumonier, S., Gotthard, G., Royant, A., Hink, M. A., and Gadella, T. W. J., Jr. (2017) mScarlet: A Bright Monomeric Red Fluorescent Protein for Cellular Imaging. Nat. Methods 14 (1), 53-56.

(46) Matoba, Y., Kihara, S., Bando, N., Yoshitsu, H., Sakaguchi, M., Kayama, K., Yanagisawa, S., Ogura, T., and Sugiyama, M. (2018) Catalytic Mechanism of the Tyrosinase Reaction toward the Tyr98 Residue in the Caddie Protein. PLoS Biol. 16 (12), No. e3000077.

(47) Heinemann, I. U., Jahn, M., and Jahn, D. (2008) The Biochemistry of Heme Biosynthesis. Arch. Biochem. Biophys. 474 (2), 238-251.

(48) Wildt, S., and Deuschle, U. (1999) CobA, a Red Fluorescent Transcriptional Reporter for Escherichia coli, Yeast, and Mammalian Cells. Nat. Biotechnol. 17 (12), 1175-1178. 